\title{
Use of Families of Euphorbiaceae for the Production of Biodiesel in Semiarid Areas ${ }^{+}$
}

\author{
Noé Anes García ${ }^{1, *}$ and Antonio Luis Marqués Sierra ${ }^{2}$ \\ 1 ELMAC Ingeniería, 33203 Gijón, Spain \\ 2 School of Mining, Energy and Materials Engineering, University of Oviedo, Independencia, 13, \\ 33003 Oviedo, Spain; almarques@gmail.com or marquesantonio@uniovi.es \\ * Correspondence: noeanes@gmail.com \\ + Presented at the Bioenergy International Conference, Portalegre, Portugal, 11-13 September 2019. \\ Published: 19 March 2021
}

\begin{abstract}
In recent years, developments made to reduce the consequences generated using petroleum products have been strengthening; therefore, biofuels have become a requirement in different countries worldwide with the objective of reducing not only the high levels of current pollution, but also mitigating the effects generated by global warming. Despite the advances that have been made in the field of research on Jatropha, it is still necessary to carry out more detailed studies aimed at achieving a better use of it, identifying the influence of its physical-chemical properties in terms of quality levels, as well as determining its behavior when mixed with palm oil to achieve a biodiesel with better yields, whose impact will be reflected mainly in the environmental field, helping to mitigate the production of greenhouse gases that are produced by petroleum products. Although currently the biofuels sector has made important advances in research, it is necessary to deepen the physical-chemical analyses both in the production and storage processes of biodiesel, so that in the future it can be fully fulfilled with the energy requirements that are currently only achieved with fossil fuels, so it is necessary to direct this research toward the development of new products with improved characteristics, especially when exposed to prolonged storage times and low temperatures.
\end{abstract}

Keywords: sustainable development; biofuel; curcas; biodiesel

\section{Introduction}

In the future, the needs of the population will not be oil, but new energy alternatives such as biodiesel, leading to a decrease in pollutants such as $\mathrm{CO}_{2}$ or sulfur elements. Biofuels for use in diesel engines are esters (methyl or ethyl) of vegetable and/or animal oils and/or fats obtained by reacting them with methanol and/or ethanol, as appropriate.

The presented work has the objective of improving the physicochemical characteristics of biodiesel biofuel through the mixture of oils. This sector has evolved due to environmental requirements, leading both public and private institutions to look for different alternatives to biodiesel production inputs [1].

However, this is a sector that has evolved to meet the current environmental requirements, which has led public and private institutions to seek new alternatives in different types of oilseeds such as curcas, which is a plant that produces an oil with attractive characteristics in terms of use as an input in the production of biodiesel.

This requires consideration of the development of analyses that allow the generation of products that can respond appropriately to these types of requirements, so it is necessary to have available methodological, technical, and technological resources and detailed knowledge so that new products can be adapt to the needs and comply with international standards, carried out at the university. The 
approach of this research involves obtaining results with experimental research of the mixture of vegetable oils to achieve a raw material with better properties to generate biodiesel with standardized quality (European Community Standard for Biodiesel, EN-14214).

When using biodiesel in areas where there are low temperatures, problems arise in the vehicles driven by biodiesel, which causes their arrest. Through this investigation, the physicochemical characteristics are studied improving the point of nine point of fluidity and oxidative stability.

A small semi-industrial plant will be carried out-the planting of curcas for the identification of different species of Euphorbiaceae (Figure 1) is the most effective method, since as it is toxic it cannot be used for human consumption, which is beneficial for local communities [2,3]. The methodology that has been carried out integrated several story activities such as the selection and identification of curcas oils that are currently produced in different semiarid areas and soils, which are characterized with the purpose of determining their physical-chemical properties, taking into account the production conditions and previous treatments, and defining which one will be used in the mixture with palm oil [4].

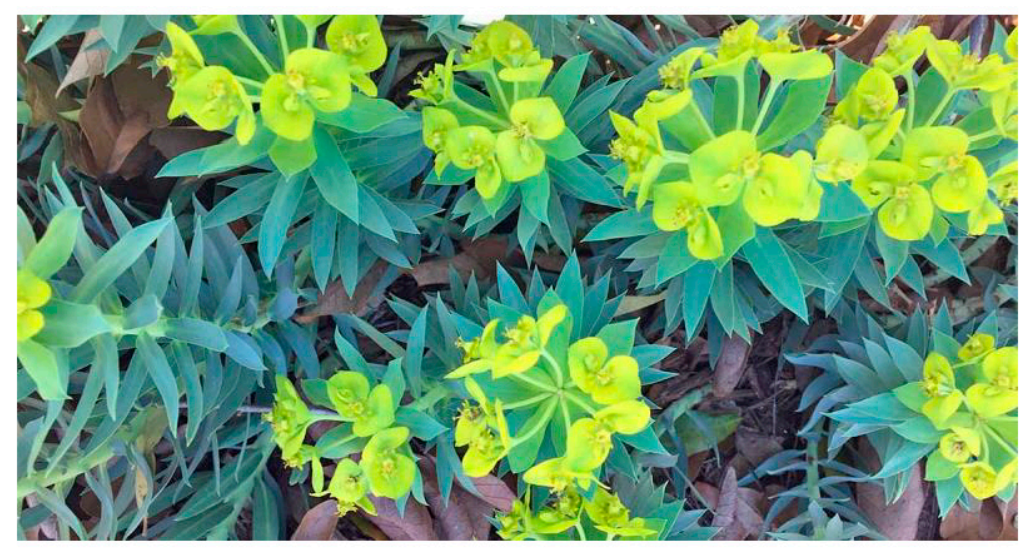

Figure 1. Euphorbiaceae [5].

Once the oils are combined, the final product is subjected to different tests in accordance with the corresponding technical standards complying with the required quality standards. The research allows an analysis to identify and characterize the different oils produced by the curcas varieties. Toxic elements, whose emissions are the compounds $\mathrm{HC}, \mathrm{CO}, \mathrm{CO}_{2}, \mathrm{SOx}$, polycyclic aromatic hydrocarbons (HAPs) and Particulate Material (MP) among other toxic elements that can affect the health of people, are reduced (see Figure 2). Once the protocols to be followed in the mixing of the oils have been defined, the final product is subjected to analysis to determine its physicochemical properties, until an improved oil is reached [6-8].
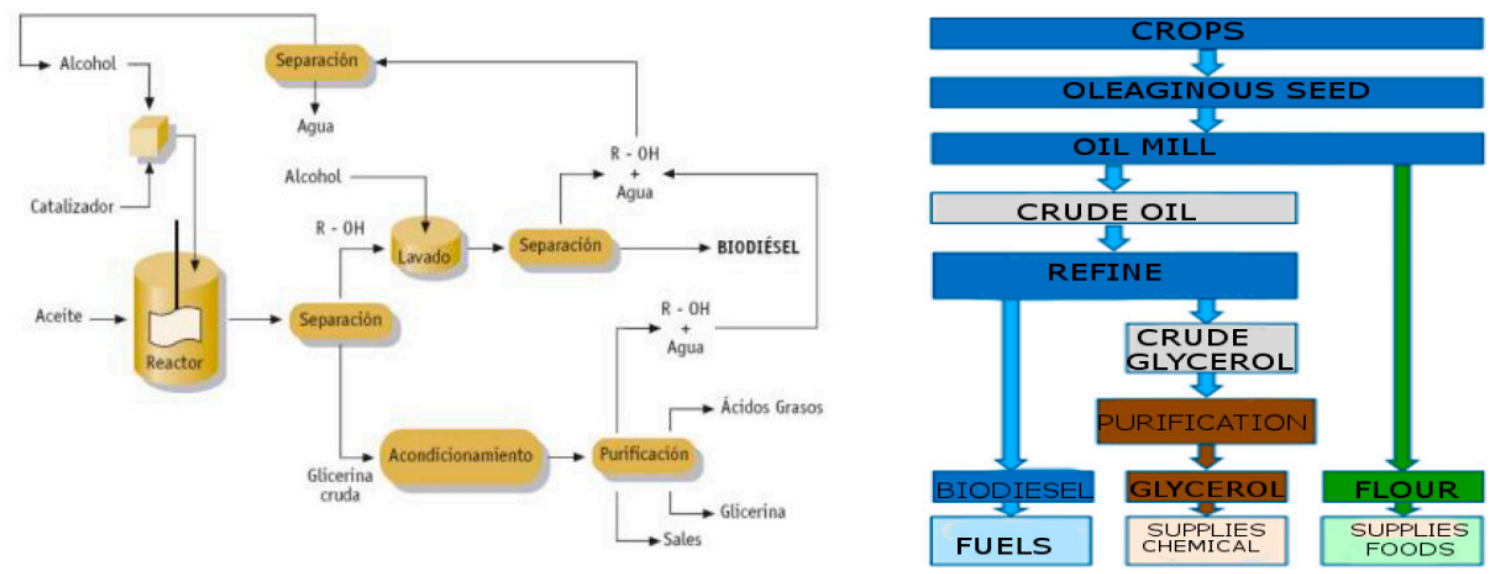

Figure 2. Biodiesel production based on [6]. 
Oil characterization from the curcas was carried out; some treatment processes of the obtained oil were determined while mixtures of oils were made to observe their improvements in the physicalchemical characteristics. The processes required to improve the properties in the combination of oils were identified and carried out. At the same time, a study has been carried out on the use of waste in the production of bioplastics from sewage sludge as fertilizer in curcas plantations; an improvement was observed [9].

\section{Conclusions}

The production of a new biofuel opens up a new market and new opportunities, since the results are subject to statistical analysis to be sure of the variation of the properties to see which oil the best for the mixture is. As we have created a biofuel from a curcas plant, which is nonedible since it is toxic, we have eliminated the problem the current biodiesel faces at low temperatures and reused a fertilizer from a waste. Through this production research, we have been able to optimize resources, making the necessary modifications in each process to achieve a high-quality final product.

The investigation of the use of the residues obtained from the production of bioplastics from sewage sludge with a high content of organic matter as fertilizer has been initiated and will continue in the future. Since it is waste with nitrogen and phosphorus contents, its use as a fertilizer is interesting.

We have guaranteed the stability of the triglycerides of the oil so that they do not generate unpleasant odors. Additionally, through the analysis of the necessary treatments, the decantation of the oil during the time that it remains stored is avoided.

We have also achieved a fatty acid composition and observed its impact on the transesterification process and conducted an analysis of the oil by acidic esterification, transesterification and alkaline esterification processes.

\section{References}

1 Ayertor, G.K.; Sunnu, A.; Parbey, J. Effect of Biodiesel Production Parameters; Elservier: New York, NY, USA, 2015.

2 Gómez, J.M. Análisis de la variación de la eficiencia en la producción de biocombustibles en América Latina. Estud. Gerenc. 2016, 32, 120-126. doi:10.1016/j.estger.2016.01.001.

3 Pinilla, J.A.G.; Campuzano, L.F.; Salvador, R.; Jorge, P.G. Caracterización Morfológica y Agronómica de la Colección Nacional de Germoplasma de Jatropha curcas L. Orinoquia 2011, 15, 131-147. doi:10.22579/20112629.8.

4 Alia, E.N.; Taya, C.I. Characterization of Biodiesel Produced from Palm Oil via Base; Elservier: New York, NY, USA, 2013.

5 Phiwngam, A.; Anusontpornperm, S.; Thanachit, S. Effects of Soil Moisture Conservation Practice, Irrigation and; Elservier: New York, NY, USA, 2016.

6 Marchetti, J.; Miguel, V.; Errazu, A. Possible Methods for Biodiesel Production; Elservier: New York, NY, USA, 2017.

7 Lu, H.; Liu, Y.; Zhou, H.; Yang, Y.; Chen, M.; Liang, B. Production of Biodiesel from Jatropha curcas L. Oil; Elservier: New York, NY, USA, 2009.

8 Koh, M.Y.; Ghazi, T.I.M. A Review of Biodiesel Production from Jatropha curcas L. Oil; Elservier: New York, NY, USA, 2011.

9 García, A. Rentabilidad de Jatropha curcas en asociación con cultivos y monocultivo en tierras de temporal en Yucatán. Rev. Mex. Agronegocios 2013, 17, 565-575.

Publisher's Note: MDPI stays neutral with regard to jurisdictional claims in published maps and institutional affiliations. 